\title{
No Dependency of a New Index for Oxygen Cost of Left Ventricular Contractility on Heart Rates in the Blood-Perfused Excised Rat Heart
}

\author{
Susumu SAKATA, Yoshimi OHGA, Takehisa ABE*, Nobuoki TABAYASHI*, \\ Shuichi KOBAYASHI ${ }^{*}$, Tsuyoshi TSUJI*, Hisaharu KOHZUKI, Hiromi MISAWA, \\ Shigeki TANIGUCHI*, and Miyako TAKAKI
}

Department of Physiology II and * Department of Surgery III, Nara Medical University, Kashihara, 634-8521 Japan

\begin{abstract}
We have reported the linear relation of myocardial oxygen consumption per beat $\left(\mathrm{VO}_{2}\right)$ and systolic pressure-volume area (PVA) in the left ventricle of the cross-circulated rat heart. The $\mathrm{VO}_{2}$ intercept (PVA-independent $\mathrm{VO}_{2}$ ) is primarily composed of $\mathrm{VO}_{2}$ for $\mathrm{Ca}^{2+}$ handling in excitation-contraction coupling and basal metabolism. Recently, we proposed a new index for oxygen cost of contractility obtainable as a slope of a linear relation between PVA-independent $\mathrm{VO}_{2}$ and left ventricular contractility. This index indicates the $\mathrm{Ca}^{2+}$ handling $\mathrm{VO}_{2}$ per unit contractility change. However, a dependency of this index on heart rate has not yet been investigated. The aim of the present study was to investigate the dependency of oxygen cost of contractility on heart rate. This is a critical point to compare this cost under different heart rates. At first we found no differences of $\mathrm{VO}_{2}$-PVA relations at 240 and 300 beats/min (bpm). Therefore, after control $\mathrm{VO}_{2}{ }^{-}$
\end{abstract}

PVA relation at $300 \mathrm{bpm}$, we gradually enhanced left ventricular contractility by $\mathrm{Ca}^{2+}$ at a midrange left ventricular volume and obtained the gradually increased PVA-independent $\mathrm{VO}_{2}$. At each contractility level, the pacing rate was alternately changed at 240 and $300 \mathrm{bpm}$. We obtained the two composite $\mathrm{VO}_{2}-\mathrm{PVA}$ relation lines and found no significant differences between the slopes of PVA-independent $\mathrm{VO}_{2}$ and left ventricular contractility relations at 240 and $300 \mathrm{bpm}$. The present results indicated no dependency of oxygen cost of left ventricular contractility on heart rates within 240-300 bpm. Based on this fact, we concluded that even under the different pacing rates within $240-300 \mathrm{bpm}$, this oxygen cost is valid for assessing cardiac mechanoenergetics, especially the economy of total $\mathrm{Ca}^{2+}$ handling in $\mathrm{E}-\mathrm{C}$ coupling. [Japanese Journal of Physiology, 51, 177-185, 2001]

Key words: end-systolic pressure-volume relation, excitation-contraction coupling, myocardial oxygen consumption, systolic pressure-volume area (PVA).

We have already reported that a linear myocardial oxygen consumption per beat $\left(\mathrm{VO}_{2}\right)$-systolic pressurevolume area (PVA) relation in the rat left ventricle (LV) [1-4] is obtainable from a curved end-systolic pressure-volume relation as in the adult canine LV, which has normal contractility [5-9]. PVA is the specific area defined as a total mechanical energy per beat $[8,9]$. The $\mathrm{VO}_{2}$ intercept of the $\mathrm{VO}_{2}-\mathrm{PVA}$ relation (PVA-independent $\mathrm{VO}_{2}$ ) mainly consists of $\mathrm{VO}_{2}$ for calcium $\left(\mathrm{Ca}^{2+}\right)$ handling in the excitation-contraction

Received on October 4, 2000; accepted on December 29, 2000

Correspondence should be addressed to: Miyako Takaki, Department of Physiology II, Nara Medical University, 840 Shijo-cho, Kashihara, 634-8521 Japan. Tel: +81-744-29-8829, Fax: +81-744-23-4696, E-mail: mtakaki@naramed-u.ac.jp

Abbreviations: $\mathrm{Ca}^{2+}$, calcium ion; E-C, excitation-contraction; e $E_{\max }$, equivalent maximal elastance; (eESP/ESV) $\mathrm{mLvv}$, equivalent end-systolic pressure-volume ratio at a midrange left ventricular volume; $E_{\max }$, maximal elastance; ESP, end-systolic pressure; ESP $\mathrm{mLV}_{\mathrm{V}}$, end-systolic pressure at a midrange left ventricular volume; LV, left ventricle; LVP, left ventricular pressure; LVV, left ventricular volume; mLVV, midrange left ventricular volume; PVA, pressure-volume area; PVA $m$ Lvv: pressure-volume area at a midrange left ventricular volume; RV, right ventricle; $\mathrm{VO}_{2}$, myocardial oxygen consumption per beat. 
(E-C) coupling and basal metabolism in rat whole heart preparations [1-4].

Recently, we proposed an "equivalent" end-systolic pressure-volume ratio at a midrange $\mathrm{LV}$ volume (mLVV) of changed LVV, (eESP/ESV) mLVV $_{\text {, as a new }}$ index for LV contractility [4]. This index is obtained as an end-systolic pressure-volume ratio of the specific virtual triangular $\mathrm{PVA}$ at an $\mathrm{mLVV}\left(\mathrm{PVA}_{\mathrm{mLVV}}\right)$ that is energetically equivalent to the real $\mathrm{PVA}_{\mathrm{mLVV}}$. We newly defined it as equivalent maximal elastance (e $\left.E_{\max }\right)$ for simplification. Plots of gradually increased PVA-independent $V \mathrm{O}_{2}$ and $\mathrm{e} E_{\max }$ values by cardiotonic agents show a highly linear relation [4]. Finally we were able to obtain the oxygen cost of LV contractility as the slope of this relation: $\mathrm{VO}_{2}$ for $\mathrm{Ca}^{2+}$ handling in the E-C coupling per unit LV contractility change [4].

However, we have not yet investigated the heart rate dependency of a new index for oxygen cost of LV contractility as well as end-systolic pressure-volume and $V_{\mathrm{O}_{2}}$-PVA relations. In individual canine hearts, the $V_{\mathrm{O}_{2}}-\mathrm{PVA}$ relation was found to be independent of heart rates (105-230 beats/min; bpm) [10], although the slight increase (10\%) in $E_{\max }$ (an LV contractility index for dog heart) was accompanied by the increase $(60 \%)$ in heart rate by pacing [11].

The aim of the present study was to investigate heart rate dependency of the oxygen cost of LV contractility as well as end-systolic pressure-volume and $\mathrm{VO}_{2}$-PVA relations. If we can find no dependency of oxygen cost of LV contractility on heart rate, we will be able to compare this index under different heart rates. This is a critical point when we evaluate the $\mathrm{Ca}^{2+}$ handling $\mathrm{VO}_{2}$ per unit contractility change by this index among diseased hearts, such as hypothyroid rat heart [12].

\section{METHODS}

Surgical preparation. Care and experiments on all rats used in the present study were carried out according to the Guiding Principles for the Care and Use of Animals in the Field of Physiological Sciences by the Council of the Physiological Society of Japan.

Experiments were performed on 12 excised, crosscirculated rat heart preparations. In each experiment, three retired breeder male Crj: Wistar rats, weighing $630 \pm 53 \mathrm{~g}$ (mean \pm SD) were purchased from Charles River Japan, Inc. (Yokohama, Japan). They were anesthetized with pentobarbital sodium $(50 \mathrm{mg} / \mathrm{kg}$, I.P. $)$ and intubated. All rats were heparinized $(1,000 \mathrm{U}$, I.V.). The largest rat was used as a blood supplier. The middle-sized rat was used as the metabolic supporter for the excised heart. The beating heart was excised from the smallest rat. All surgical procedures were previously reported in detail $[1,2]$.

In the excised beating heart maintained at $37^{\circ} \mathrm{C}$, a thin latex balloon (balloon material volume $0.08 \mathrm{ml}$ ) was inserted into the LV and primed with water. The balloon was connected to a pressure transducer (Life Kit DX-312, Nihon Kohden, Tokyo, Japan). Balloon water volume was changed with a $0.5 \mathrm{ml}$ precision glass syringe (minimum scale: $0.005 \mathrm{ml}$ ). LV pressure (LVP) was measured with this pressure transducer. The balloon developed no pressure and thus was unstretched as long as its volume was below approximately $0.25-0.3 \mathrm{ml}$. Thus LVV was changed and measured by adjusting the intraballoon water volume with the syringe in $0.05 \mathrm{ml}$ steps between 0.08 and $0.28 \mathrm{ml}$. Systolic unstressed volume $\left(V_{0}=0.08 \mathrm{ml}\right)$ should be determined as the volume at which peak isovolumic pressure and thus PVA were zero.

LV epicardial electrocardiogram was recorded and heart rate was maintained constant at 300 and $240 \mathrm{bpm}$ by electrical pacing of the right atrium. Systemic arterial blood pressure of the support rat served as coronary perfusion pressure $(100-130 \mathrm{mmHg})$. Arterial $\mathrm{pH}, \mathrm{PO}_{2}$, and $\mathrm{PCO}_{2}$ of the support rat and thus the perfused blood were maintained within their physiological ranges with supplemental oxygen and sodium bicarbonate throughout the experiment.

Oxygen consumption. Cardiac $\mathrm{O}_{2}$ consumption was obtained as the product of coronary flow and coronary arteriovenous $\mathrm{O}_{2}$ content difference. As shown previously [1-3], the $\mathrm{VO}_{2}$-PVA relation was linear in the rat $\mathrm{LV}$. The $\mathrm{VO}_{2}$ intercept represents PVAindependent $\mathrm{VO}_{2}$. The right ventricle (RV) was kept collapsed by continuous hydrostatic drainage of the coronary venous return; thus the RV PVA and the PVA-dependent $V_{\mathrm{O}_{2}}$ were assumed to be negligible. The RV component of PVA-independent $V \mathrm{O}_{2}$ was calculated by multiplying biventricular PVA-independent $\mathrm{VO}_{2}$ in each contractile state with the ratio of $\mathrm{RV}$ weight divided by the sum of RV and LV weights. The RV PVA-independent $V_{\mathrm{O}_{2}}$ was subtracted from the total $V_{\mathrm{O}_{2}}$ to yield $\mathrm{LV} V \mathrm{OO}_{2}$. At the end of the experiment, the LV, including the septum, and the RV free walls were separately weighed. They were $1.06 \pm 0.07$ and $0.31 \pm 0.04 \mathrm{~g}(n=12)$. These $\mathrm{LV}$ values were also used for normalizing LVV.

Experimental protocol. LVP, $\mathrm{VO}_{2}$, and PVA data were obtained at five or six changed volumes $(0.08-0.23 \mathrm{ml} ; 0.08-0.28 \mathrm{ml}$ in rare cases) in each heart (volume run). LVV was increased in steps up to an end-diastolic pressure of $10 \mathrm{mmHg}$ in control volume run. An mLVV corresponded to 0.16 $\left(=\left[0.23-V_{0}\right] / 2+V_{0}\right) \mathrm{ml}$. The value of mLVV normal- 
ized by $\mathrm{LV}$ mass to $1 \mathrm{~g}$ ranged from 0.13 to $0.17 \mathrm{ml} / \mathrm{g}$. The mean of mLVV was $0.15( \pm 0.01) \mathrm{ml} / \mathrm{g}$ in 12 hearts. End-systolic pressure at this $\mathrm{mLVV}\left(\mathrm{ESP}_{\mathrm{mLVV}}\right)$ was 60 to $70 \%$ of the maximum ESP, at which the changes in LV mechanoenergetics induced by various interventions could be detected sensitively. $\mathrm{PVA}_{\mathrm{mLVV}}$ was relatively small, but valid for practical use. The mean of systolic unstressed volume $\left(V_{0}\right)$ normalized by $\mathrm{LV}$ mass to $1 \mathrm{~g}$ was $0.08( \pm 0.01) \mathrm{ml} / \mathrm{g}$.

Different LVV loading runs in the control (control volume run) were performed with no inotropic interventions at 240 and $300 \mathrm{bpm}$ in 6 hearts. In a different group of 6 hearts, after the control volume run at $300 \mathrm{bpm}, \mathrm{Ca}^{2+}$ inotropism run at a given mLVV and $\mathrm{Ca}^{2+}$ volume run at the same LVVs as used in the control volume run were performed during intracoronary infusion of $1 \% \mathrm{CaCl}_{2}$ solution. During a $\mathrm{Ca}^{2+}$ inotropism run 240- and 300-bpm electrical pacings were both alternately performed at each contractile state. The infusion rate was increased in steps up to 7 or $10 \mathrm{ml} / \mathrm{h}$ until end-systolic pressure (ESP) stopped to increase. Each arterial blood $\mathrm{Ca}^{2+}$ concentration of the excised hearts was measured by RADIOMETER ABL SYSTEM 505 (Copenhagen, Denmark), showing $1.2 \pm 0.2 \mathrm{mmol} / l$ in the control and $2.8 \pm 0.7$ $\mathrm{mmol} / \mathrm{l}$ at the maximal $\mathrm{Ca}^{2+}$ infusion rate. Throughout the experiment, hematocrit decreased by less than $1.4 \%$, indicating neither hemolysis nor hemodilution.

Data sampling was started 6 min after the onset of $1 \% \mathrm{CaCl}_{2}$ infusion. In every volume run and/or $\mathrm{Ca}^{2+}$ inotropism run, a steady state was reached $2-3 \mathrm{~min}$ after changing LVV and/or 6 min after changing the infusion rate of $1 \% \mathrm{CaCl}_{2}$. In each steady state, data were sampled at $500 \mathrm{~Hz}$ for $2 \mathrm{~s}$ simultaneously, and the sampling was usually repeated 3 times at intervals of $0.5-1 \mathrm{~min}$.

Data analysis. We determined PVA by the method described below because the end-systolic pressure-volume relation of the rat LV was an upward convex curve [1-3, 13-15]. We fitted the end-systolic and end-diastolic pressure-volume points by the same exponential functions as used in the previous studies $[1,2,4,13,14,16]$ and obtained the best-fit end-systolic and end-diastolic pressure-volume relations.

PVA is defined as the pressure-volume area circumscribed by the curvilinear end-systolic pressurevolume relation, end-diastolic pressure-volume relation, and the systolic portion of the ventricular pressure-volume trajectory $[1,2,4,13]$. The area under the end-systolic pressure-volume relation is obtained by integration of the best-fit exponential function. The area under the end-diastolic pressure-volume relation is assumed to be zero within the same LVV range be- cause of the end-diastolic pressure being lower than $10 \mathrm{mmHg}[1-4,13,14]$. Finally, PVA is normalized by $\mathrm{LV}$ mass to $1 \mathrm{~g}$.

PVA-independent $\mathrm{VO}_{2}$. We first obtained control end-systolic pressure-volume relation from the observed end-systolic pressure-volume data at five or six different LVVs as a best-fit exponential function curve. During $\mathrm{Ca}^{2+}$ inotropism run at an $\mathrm{mLVV}$, endsystolic pressure-volume, and $\mathrm{VO}_{2}$ data were sampled. We then obtained each end-systolic pressure-volume relation as a best-fit curve to the observed end-systolic pressure-volume data and those at $V_{0}$. We calculated $\mathrm{PVA}_{\mathrm{mLVV}}$ by integrating each end-systolic pressurevolume relation from $V_{0}$ up to the $\mathrm{mLVV}$.

We then obtained the two composite $\mathrm{VO}_{2}$-PVA relations at the mLVV during stepwise increased $\mathrm{Ca}^{2+}$ infusion at 240 and $300 \mathrm{bpm}$. The $\mathrm{VO}_{2}-\mathrm{PVA}$ relation of the $\mathrm{Ca}^{2+}$ volume run at the maximal rate of $\mathrm{Ca}^{2+}$ infusion at $300 \mathrm{bpm}$ shifted upward in parallel to the control $\mathrm{VO}_{2}-\mathrm{PVA}$ relation at $300 \mathrm{bpm}$, as previously reported [1, 4]. To obtain the $\mathrm{VO}_{2}$-intercept values (PVA-independent $V \mathrm{O}_{2}$ values), we drew the lines including data of each $\mathrm{VO}_{2}$-PVA at the mLVV during the $\mathrm{Ca}^{2+}$ infusion, in parallel to the control $\mathrm{VO}_{2}$-PVA relation line at $300 \mathrm{bpm}$. Basal metabolic $\mathrm{VO}_{2}$ was unaltered during the $\mathrm{Ca}^{2+}$ infusion, thus indicating that the increased PVA-independent $V \mathrm{O}_{2}$ values are due to the increased $\mathrm{VO}_{2}$ for $\mathrm{Ca}^{2+}$ handling in the E-C coupling.

LV contractility. As an index for LV contractility, we have proposed an "equivalent" ESP-V ratio at an $\mathrm{mLVV}$, (eESP/ESV) $)_{\mathrm{mLV}}$ [4]. We newly defined it as $\mathrm{e} E_{\max }$ (equivalent maximal elastance). This index is obtained by calculating the end-systolic pressure-volume ratio of the specific virtual triangular $\mathrm{PVA}_{\mathrm{mLVV}}$ that is energetically equivalent to the real $\mathrm{PVA}_{\mathrm{mLVV}}$ [4]. $\mathrm{PVA}_{\mathrm{mLVV}}$ has been proposed to be a good index for evaluating rat LV contractility in terms of mechanoenergetics [1, 2, 13-15].

Oxygen cost of LV contractility. The oxygen cost of LV contractility was obtained as the slope of linear relation between PVA-independent $\mathrm{VO}_{2}$ and $\mathrm{e} E_{\max }$. This slope is an index quantifying $\mathrm{VO}_{2}$ for $\mathrm{Ca}^{2+}$ handling in the E-C coupling per unit LV contractility change.

Statistics. An analysis of covariance (ANCOVA) was applied to compare the paired regression lines of $\mathrm{LV} \mathrm{OO}_{2}$-PVA relation obtained by control volume runs at 240 and $300 \mathrm{bpm}$ in each heart, and those by control and $\mathrm{Ca}^{2+}$ volume runs at $300 \mathrm{bpm}$. A comparison of paired individual values was performed by the paired $t$-test. A value of $p<0.05$ was considered statistically significant. All data are expressed as mean \pm SD. 

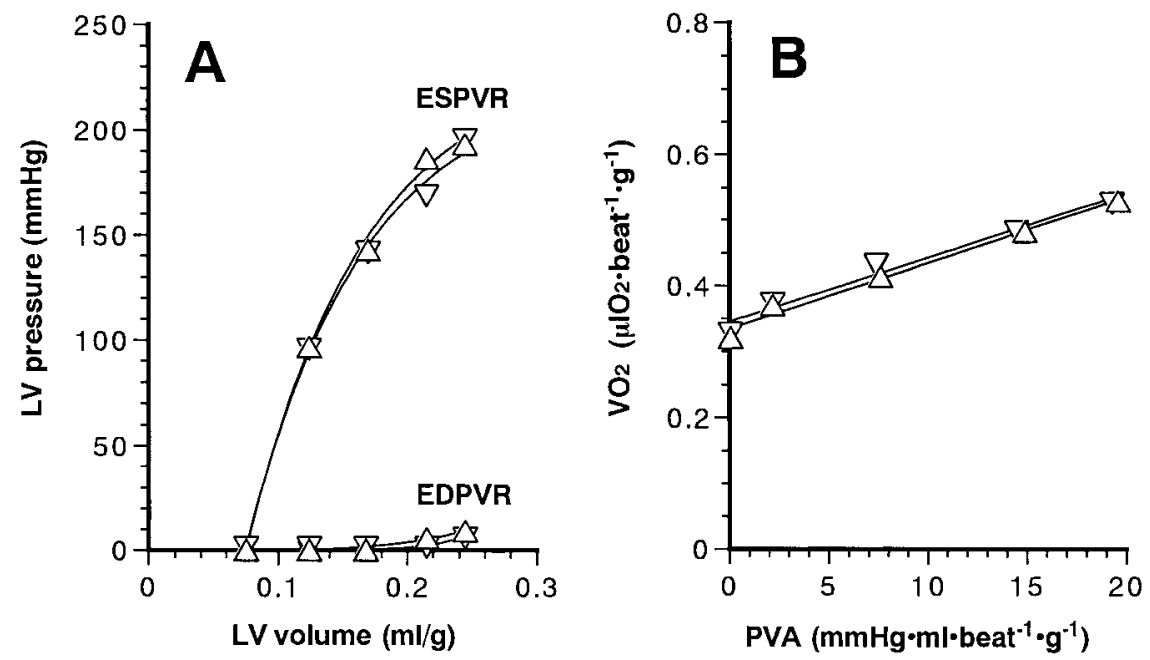

Fig. 1. Left ventricular end-systolic pressure-volume relations (ESPVRs) and end-diastolic pressure-volume relations (EDPVRs) from experimentally obtained pressure-volume data were best-fit curves by $P_{\mathrm{es}}=A\left\{1-\exp \left[-B\left(V-V_{0}\right)\right]\right\}$ and by $P_{\mathrm{ed}}=A^{\prime}\left\{\exp \left[B^{\prime}\left(V-V_{\mathrm{u}}\right)\right]-1\right\}$ at $240-(\nabla)$ and $300-\mathrm{bpm}$ pacing $(\triangle)$ in one heart (A). Left ventricular oxygen consumption per beat $\left(\mathrm{VO}_{2}\right)$-PVA (systolic pressure-volume area) linear relations at 240$(\nabla)$ and $300-b p m$ pacing $(\triangle)$ in the same heart (B). $\nabla, V_{O_{2}}=0.0098 \mathrm{PVA}+$ 0.345. $\triangle, V_{2}=0.0100 \mathrm{PVA}+0.334$.

Table 1. Variables of left ventricular mechanics at pacing rates of 240 and $300 \mathrm{bpm}$.

\begin{tabular}{|c|c|c|c|c|c|c|c|c|}
\hline Exp. No. & & $\begin{array}{c}A \\
(\mathrm{mmHg})\end{array}$ & $\begin{array}{c}B \\
(1 / \mathrm{ml})\end{array}$ & $\begin{array}{c}V_{0} \\
(\mathrm{ml} / \mathrm{g})\end{array}$ & $\begin{array}{l}\mathrm{ESP}_{\max } \\
(\mathrm{mmHg})\end{array}$ & $\begin{array}{l}\mathrm{ESP}_{\mathrm{mLVV}} \\
(\mathrm{mmHg})\end{array}$ & $\begin{array}{c}\mathrm{PVA}_{\mathrm{mLVV}} \\
\left(\mathrm{mmHg} \cdot \mathrm{ml} \cdot \text { beat }^{-1} \cdot \mathrm{g}^{-1}\right)\end{array}$ & $\begin{array}{l}\mathrm{mLVV} \\
(\mathrm{ml} / \mathrm{g})\end{array}$ \\
\hline \multirow[t]{2}{*}{1} & HR 240 & 220.6 & 10.8 & 0.06 & 163.3 & 110.2 & 3.45 & 0.13 \\
\hline & HR 300 & 223.8 & 8.8 & 0.06 & 165.0 & 96.4 & 2.77 & 0.13 \\
\hline \multirow[t]{2}{*}{2} & HR 240 & 231.7 & 9.4 & 0.08 & 195.5 & 120.4 & 5.08 & 0.16 \\
\hline & HR 300 & 189.5 & 12.6 & 0.08 & 180.1 & 118.4 & 5.29 & 0.16 \\
\hline \multirow[t]{2}{*}{3} & HR 240 & 174.2 & 14.4 & 0.09 & 168.2 & 123.5 & 6.85 & 0.17 \\
\hline & HR 300 & 162.8 & 16.4 & 0.09 & 156.5 & 123.0 & 6.96 & 0.17 \\
\hline \multirow[t]{2}{*}{4} & HR 240 & 176.3 & 9.6 & 0.08 & 136.2 & 93.0 & 4.08 & 0.16 \\
\hline & HR 300 & 158.3 & 11.0 & 0.08 & 130.0 & 91.6 & 4.09 & 0.16 \\
\hline \multirow[t]{2}{*}{5} & HR 240 & 223.5 & 11.0 & 0.08 & 196.4 & 125.6 & 5.10 & 0.15 \\
\hline & HR 300 & 234.1 & 10.7 & 0.08 & 195.0 & 129.5 & 5.20 & 0.15 \\
\hline \multirow[t]{2}{*}{6} & HR 240 & 312.3 & 7.2 & 0.07 & 180.0 & 125.1 & 4.31 & 0.14 \\
\hline & HR 300 & 309.7 & 6.3 & 0.07 & 192.1 & 111.6 & 3.92 & 0.14 \\
\hline Mean & HR 240 & 223.1 & 10.4 & 0.08 & 173.3 & 116.3 & 4.81 & 0.15 \\
\hline SD & & 45.9 & 2.2 & 0.01 & 20.7 & 11.6 & 1.08 & 0.01 \\
\hline Mean & HR 300 & 213.0 & 11.0 & 0.08 & 169.8 & 111.8 & 4.71 & 0.15 \\
\hline SD & & 51.6 & 3.1 & 0.01 & 22.4 & 13.7 & 1.32 & 0.01 \\
\hline
\end{tabular}

Exp. No., experiment number; HR, heart rate; $A$ and $B$, fitting parameters in a equation $P_{\mathrm{es}}=A\left\{1-\exp \left[-B\left(V-V_{0}\right)\right]\right\}$; $V_{0}, \mathrm{vol}-$ ume intercept of end-systolic pressure-volume relation in control volume run; $\mathrm{ESP}_{\max }$, maximum end-systolic pressure in control volume run; ESP ${ }_{m L V}$, end-systolic pressure at a midrange left ventricular volume; PVA $A_{m L v}$, pressure-volume area at a midrange left ventricular volume; $\mathrm{mLVV}$, midrange left ventricular volume; SD, standard deviation of the mean values.

\section{RESULTS}

\section{End-systolic pressure-volume and $\mathrm{VO}_{2}$-PVA relations at 240 and $300 \mathrm{bpm}$}

Representative control end-systolic pressure-volume and end-diastolic pressure-volume relations obtained from pressure-volume data at five to six varied LVVs at pacing rates of 240 and $300 \mathrm{bpm}$ are shown in Fig. 1A. Each end-systolic pressure-volume relation at 240- and 300-bpm pacing was superimposable. The mean of $\mathrm{ESP}_{\mathrm{mLVV}}$ was $67.4 \pm 3.5$ and $66.3 \pm 7.1 \%$ of the maximum ESP at 240 and $300 \mathrm{bpm}$, respectively $(n=6)$. As shown in Table 1 , all variables of $L V$ mechanics showed no differences between 240- and 300-bpm pacing.

Despite the curved end-systolic pressure-volume relation, there was a linear relation between $\mathrm{VO}_{2}$ and PVA; $\mathrm{OO}_{2}$ increased in steps with increased PVA (Fig. 1B). The mean slopes of the $\mathrm{VO}_{2}-\mathrm{PVA}$ relations at 240 - and $300-$ bpm pacing were $0.012 \mu l \quad \mathrm{O}_{2}$. $\mathrm{mmHg}{ }^{-1} \cdot \mathrm{ml}^{-1} \quad\left(=1.2 \times 10^{-5} \mathrm{ml} \quad \mathrm{O}_{2} \cdot \mathrm{mmHg}^{-1} \cdot \mathrm{ml}^{-1}\right)$ and $0.011 \mu \mathrm{O}_{2} \cdot \mathrm{mmHg}^{-1} \cdot \mathrm{ml}^{-1}\left(=1.1 \times 10^{-5} \mathrm{ml} \mathrm{O}_{2}\right.$. $\mathrm{mmHg}{ }^{-1} \cdot \mathrm{ml}^{-1}$ ). Its mean $\mathrm{VO}_{2}$ intercept (PVA-independent $\mathrm{VO}_{2}$ ) at each pacing rate was $0.30 \mu \mathrm{l} \mathrm{O}_{2}$. beat ${ }^{-1} \cdot \mathrm{g}^{-1}\left(0.030 \mathrm{ml} \mathrm{O}{ }_{2} \cdot\right.$ beat $\left.^{-1} \cdot 100 \mathrm{~g}^{-1}\right)$ and $0.28 \mu \mathrm{l}$ $\mathrm{O}_{2} \cdot$ beat $^{-1} \cdot \mathrm{g}^{-1}\left(0.028 \mathrm{ml} \mathrm{O}_{2} \cdot\right.$ beat $\left.^{-1} \cdot 100 \mathrm{~g}^{-1}\right)$ in the 6 
Heart Rate and Oxygen Cost of Contractility

Table 2. Slope and $\mathrm{VO}_{2}$-intercept of control $\mathrm{VO}_{2}$-PVA relation at pacing rates of 240 and $300 \mathrm{bpm}$.

\begin{tabular}{|c|c|c|c|c|c|c|}
\hline \multirow{3}{*}{ Exp. No. } & \multicolumn{4}{|c|}{ Control $\mathrm{VO}_{2}-\mathrm{PVA}$ relation } & \multirow{2}{*}{\multicolumn{2}{|c|}{$\begin{array}{c}\text { Observed } \\
\mathrm{O}_{2} \text {-intercept } \\
\left(\mu \mid \mathrm{O}_{2} \cdot \text { beat }^{-1} \cdot \mathrm{g}^{-1}\right)\end{array}$}} \\
\hline & \multicolumn{2}{|c|}{$\begin{array}{c}\text { Slope } \\
\left(\times 10^{-2} \mu \mathrm{l} \mathrm{O}_{2} \cdot \mathrm{mmHg}^{-1} \cdot \mathrm{ml}^{-1}\right)\end{array}$} & \multicolumn{2}{|c|}{$\begin{array}{l}\text { Calculated } \mathrm{VO}_{2} \text {-intercept } \\
\qquad\left(\mu \mid \mathrm{O}_{2} \cdot \text { beat }^{-1} \cdot \mathrm{g}^{-1}\right)\end{array}$} & & \\
\hline & HR 240 & HR 300 & HR 240 & HR 300 & HR 240 & HR 300 \\
\hline 1 & 1.13 & 1.31 & 0.21 & 0.20 & 0.20 & 0.19 \\
\hline 2 & 1.18 & 0.92 & 0.33 & 0.31 & 0.31 & 0.29 \\
\hline 3 & 0.88 & 0.69 & 0.25 & 0.24 & 0.25 & 0.25 \\
\hline 4 & 1.26 & 0.99 & 0.25 & 0.25 & 0.24 & 0.24 \\
\hline 5 & 0.98 & 1.00 & 0.35 & 0.33 & 0.33 & 0.32 \\
\hline 6 & 1.58 & 1.57 & 0.41 & 0.37 & 0.39 & 0.38 \\
\hline Mean & 1.17 & 1.08 & 0.30 & $0.28^{*}$ & 0.29 & 0.28 \\
\hline SD & 0.22 & 0.28 & 0.07 & 0.06 & 0.06 & 0.06 \\
\hline
\end{tabular}

Exp. No., experiment number; $\mathrm{HR}$, heart rate; $\mathrm{VO}_{2}$, myocardial oxygen consumption per beat; PVA, pressure-volume area; $\mathrm{SD}$, standard deviation of the mean values. ${ }^{*}$ Significantly different from the mean value at $240 \mathrm{bpm} ; p<0.05$.
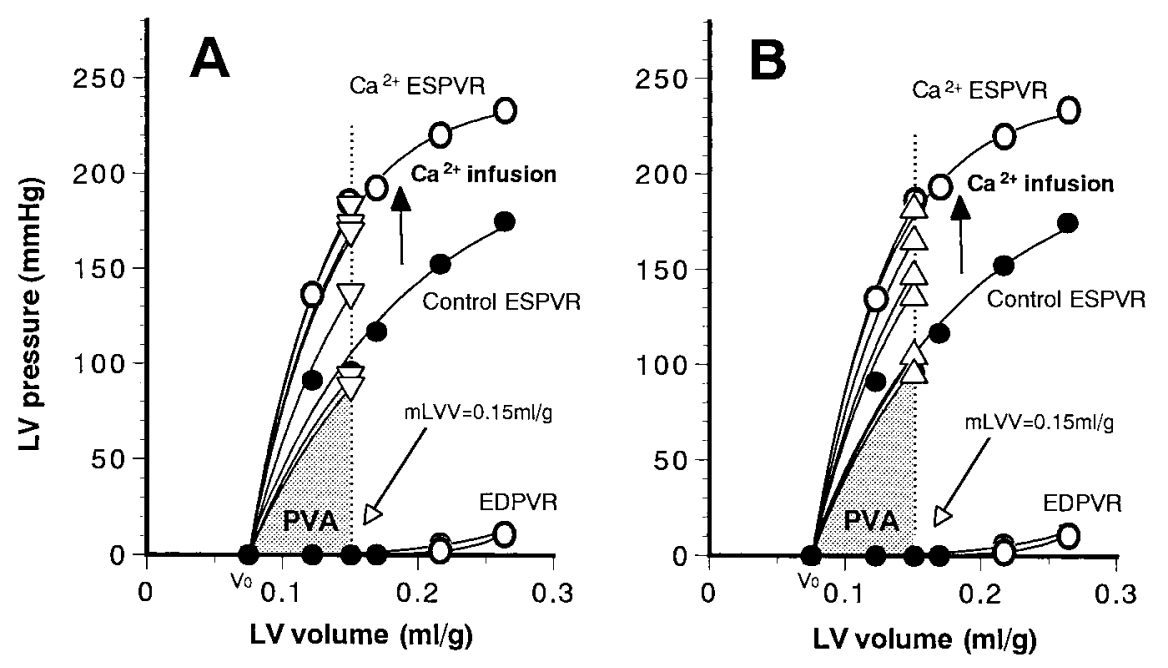

Fig. 2. Each example of experimentally obtained left ventricular (LV) pressure-volume data at a midrange LV volume (mLVV) during calcium $\left(\mathrm{Ca}^{2+}\right)$ intracoronary infusion at 240-bpm pacing $(A)$ and at 300-bpm pacing (B). Control and $\mathrm{Ca}^{2+}$ end-systolic pressure-volume relations (ESPVRs) and end-diastolic pressure-volume relations (EDPVRs) in $A$ and $B$ were obtained at $300-b p m$ pacing. A: Pressure-volume data at 240-bpm pacing $(\nabla)$ during $\mathrm{Ca}^{2+}$ infusion at increased rates in steps at an $\mathrm{mLVV}$. B: Pressure-volume data at 300-bpm pacing $(\triangle)$ during the same $\mathrm{Ca}^{2+}$ infusion. PVA (systolic pressurevolume area; shaded area) at an $\mathrm{mLVV}$ during $\mathrm{Ca}^{2+}$ infusion was obtained by integrating each ESPVR curve from $V_{0}$ to a given $\mathrm{mLVV}(=0.15 \mathrm{ml} / \mathrm{g})$.

rat hearts (Table 2). Mean slopes showed no differences, but mean $\mathrm{VO}_{2}$ intercepts calculated showed a statistically significant difference $(p<0.05)$ between 240- and 300-bpm pacing. However, the mean $\mathrm{VO}_{2}$ intercept values actually observed were 0.29 and $0.28 \mu \mathrm{O}_{2} \cdot$ beat $^{-1} \cdot \mathrm{g}^{-1}$ and showed no significant differences between 240- and 300-bpm pacing (Table 2). Therefore we judged that the difference in the mean $\mathrm{VO}_{2}$ intercepts is negligible.

Changes in end-systolic pressure-volume and $\mathrm{VO}_{2}$-PVA data during intracoronary $\mathrm{Ca}^{2+}$ infusion under 240- and 300-bpm pacing

After the control volume run at $300 \mathrm{bpm}$ was performed in a different group of 6 hearts, ESP at an $\mathrm{mLVV}(=0.15 \mathrm{ml} / \mathrm{g})$ increased in steps with the in- creased rates of $\mathrm{Ca}^{2+}$ infusion (triangles in Fig. 2). $\mathrm{VO}_{2}$-PVA data points deviated right-upwardly on the composite $\mathrm{VO}_{2}$-PVA lines at 240 and $300 \mathrm{bpm}$ (triangles in Fig. $3 \mathrm{~A}$ ). $V \mathrm{O}_{2}$ and PVA at the mLVV increased by $44.2 \pm 18.4$ and $70.9 \pm 36.9 \% \quad(p<0.001$ and $p<$ $0.01)$ at $240 \mathrm{bpm}$, and by $41.6 \pm 12.4$ and $58.2 \pm 27.0 \%$ $(p<0.001$ and $p<0.01)$ at $300 \mathrm{bpm}$ at the maximal $\mathrm{Ca}^{2+}$ infusion rate $(7$ or $10 \mathrm{ml} / \mathrm{h})$. The composite $\mathrm{VO}_{2^{-}}$ PVA relations at 240 and $300 \mathrm{bpm}$ could be superimposed (Fig. 3A). The blood $\mathrm{Ca}^{2+}$ concentration reached $2.8 \mathrm{mmol} / l$.

Changes in end-systolic pressure-volume and $\mathrm{VO}_{2}$-PVA relations during intracoronary $\mathrm{Ca}^{2+}$ infusion under $300-\mathrm{bpm}$ pacing

Each ESP at the LVVs corresponding to the control 

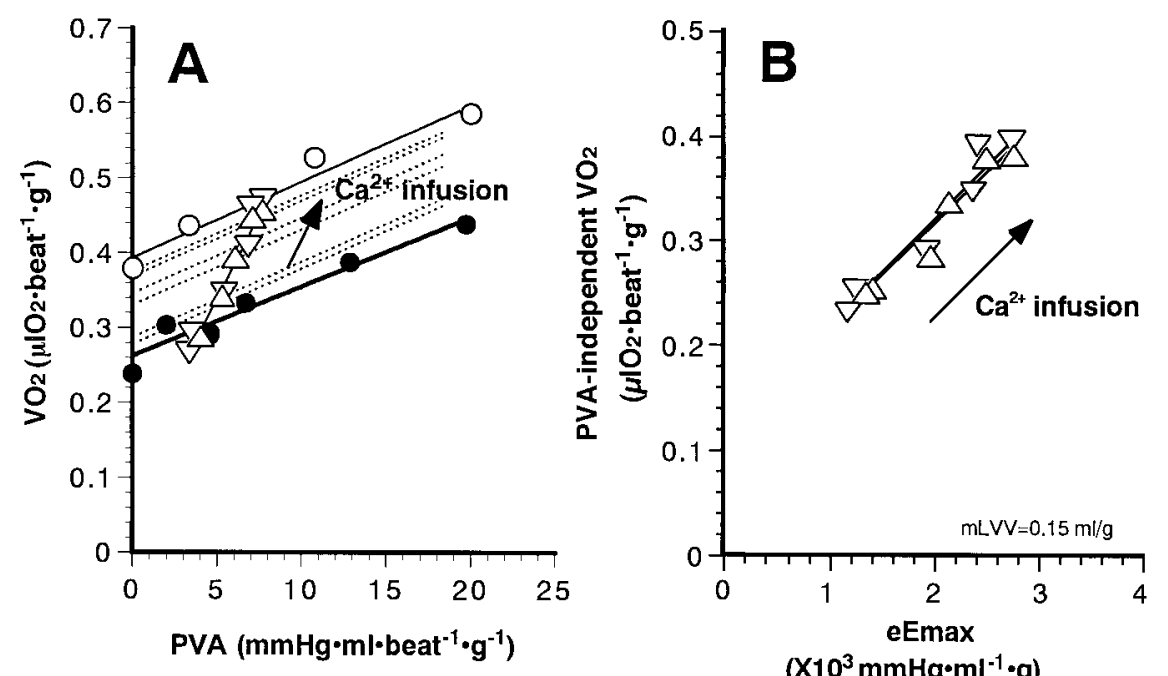

$\left(X 10^{3} \mathrm{mmHg}^{\prime} \mathrm{ml}^{-1} \cdot \mathrm{g}\right)$
Fig. 3. A: Left ventricular (LV) oxygen consumption per beat $\left(\mathrm{VO}_{2}\right)$-PVA (systolic pressure-volume area) relations in the control (solid circles) and at maximally enhanced contractile state (open circles) by calcium $\left(\mathrm{Ca}^{2+}\right)$ intracoronary infusion in the same heart as in Fig. 2. Each composite $\mathrm{VO}_{2}-\mathrm{PVA}$ relation during $\mathrm{Ca}^{2+}$ infusion at increased rates in steps at a midrange $\mathrm{LV}$ volume $(\mathrm{mLVV}=0.15 \mathrm{ml} / \mathrm{g})$ at 240 bpm pacing $(\nabla)$ and $300-b p m$ pacing $(\triangle)$ could be superimposed. Dotted lines indicate each $\mathrm{VO}_{2}$-PVA relation drawn from each $\mathrm{VO}_{2}$-PVA data point, which was obtained during $\mathrm{Ca}^{2+}$ infusion. The slope of each $\mathrm{VO}_{2}-\mathrm{PVA}$ relation corresponds to that of the $\mathrm{VO}_{2}$ -

PVA relation in the control at 300-bpm pacing. The intercept of each $\mathrm{VO}_{2}-\mathrm{PVA}$ relation corresponds to each PVA-independent $\mathrm{VO}_{2}$. B: Oxygen cost of left ventricular (LV) contractility (e $\left.E_{\max }\right)$ during $\mathrm{Ca}^{2+}$ infusion in the same heart as in $\mathrm{A}$. The relations between PVA-independent $V_{O_{2}}$ and $e E_{\max }$ during $\mathrm{Ca}^{2+}$ infusion at 240-bpm pacing $(\nabla)$ and $300-\mathrm{bpm}$ pacing $(\triangle)$ are highly linear and can be superimposed. The correlation coefficients of these regression lines are 0.96 and 0.97 . The slopes of these relation lines denote the oxygen costs of $\mathrm{LV}$ contractility $\left(=1.1 \times 10^{-4} \mu \mathrm{l} \mathrm{O}_{2} \cdot \mathrm{ml}^{\prime} \mathrm{mmHg}^{-1} \cdot \mathrm{beat}^{-1} \cdot \mathrm{g}^{-2}\right.$ at $240 \mathrm{bpm}$ and $1.0 \times 10^{-4} \mu \mathrm{O}_{2} \cdot \mathrm{ml} \cdot \mathrm{mmHg}^{-1} \cdot$ beat $^{-1} \cdot \mathrm{g}^{-2}$ at $300 \mathrm{bpm}$ ) in this heart. A midrange LV volume (mLVV) was $0.15 \mathrm{ml} / \mathrm{g}$.

volume run increased, and the end-systolic pressurevolume relation curve became steeper and reached an LV pressure level higher than control under the $\mathrm{Ca}^{2+}$ infusion $(7$ or $10 \mathrm{ml} / \mathrm{h})$ in the 6 hearts at $300 \mathrm{bpm}$ (open circles in Fig. 2). $\mathrm{VO}_{2}$ correlated linearly with PVA in each of the control and $\mathrm{Ca}^{2+}$ volume run at $300 \mathrm{bpm}$. The linear $\mathrm{VO}_{2}-\mathrm{PVA}$ relation shifted upward with the enhanced contractile state (Fig. 3A). The $\mathrm{VO}_{2}$-PVA data points deviated right-upwardly from the control $\mathrm{VO}_{2}-\mathrm{PVA}$ data points at each LVV (circles in Fig. 3). The slope of each $\mathrm{VO}_{2}$-PVA relation in the $\mathrm{Ca}^{2+}$ volume run was not significantly different from that in the control volume run, but the $\mathrm{VO}_{2}$ intercept value of each relation significantly increased $(p<0.01$ by ANCOVA) in all 6 hearts, as previously reported $[1,4]$.

\section{Oxygen cost of LV contractility during $\mathrm{Ca}^{2+}$ intracoronary infusion}

When the $\mathrm{Ca}^{2+}$ infusion rate was increased in steps, the PVA-independent $\mathrm{VO}_{2}$ increased accompanied with the gradually increased PVA (shaded area in Fig. 2) at an mLVV of $0.15 \mathrm{ml} / \mathrm{g}$ at 240 and $300 \mathrm{bpm}$. Both increases in PVA-independent $V_{\mathrm{O}_{2}}$ at 240 and $300 \mathrm{bpm}$ are due to the increased total $\mathrm{Ca}^{2+}$ handling in the E-C coupling. The increases in $V_{2}$ intercept (PVA-independent $V \mathrm{O}_{2}$ ) were proportional to those in $\mathrm{LV}$ contractility (Fig. 3A), indicating that the $\mathrm{VO}_{2}$ intercept reflected well the LV contractility under the constant slope of the $\mathrm{VO}_{2}-\mathrm{PVA}$ relation at 240 and $300 \mathrm{bpm}$.

Plots of PVA-independent $V \mathrm{O}_{2}$ and $\mathrm{e} E_{\max }$ values calculated from $\mathrm{PVA}_{\mathrm{mLVV}}$ showed the highly linear relation (Fig. 3B) $(r=0.92 \pm 0.07$ at $240 \mathrm{bpm}$ and $r=$ $0.95 \pm 0.03$ at $300 \mathrm{bpm} ; n=6$ ). We defined the slope of this relation as the oxygen cost of LV contractility. Mean oxygen costs of LV contractility were (1.4 \pm $0.4) \times 10^{-4} \mu \mathrm{l} \quad \mathrm{O}_{2} \cdot \mathrm{ml} \cdot \mathrm{mmHg}^{-1} \cdot$ beat $^{-1} \cdot \mathrm{g}^{-2} \quad(=[1.4 \pm$ $0.4] \times 10^{-3} \mathrm{ml} \mathrm{O}_{2} \cdot \mathrm{ml} \cdot \mathrm{mmHg}^{-1} \cdot$ beat $^{-1} \cdot 100 \mathrm{~g}^{-2}$ for comparison with that in the canine LV) at $240 \mathrm{bpm}$ and $(1.5 \pm 0.4) \times 10^{-4} \mu \mathrm{l} \mathrm{O}_{2} \cdot \mathrm{ml} \cdot \mathrm{mmHg}^{-1} \cdot$ beat $^{-1} \cdot \mathrm{g}^{-2}$ $\left(=[1.5 \pm 0.4) \times 10^{-3} \mathrm{ml} \quad \mathrm{O}_{2} \cdot \mathrm{ml} \cdot \mathrm{mmHg}^{-1} \cdot\right.$ beat $^{-1} \cdot 100$ $\mathrm{g}^{-2}$ ) at $300 \mathrm{bpm}$ (Table 3). There was no significant difference between them at 240 and $300 \mathrm{bpm}$.

\section{DISCUSSION}

As for an index assessing for LV contractility, we have well used $E_{\max }$ (maximal elastance; end-systolic pressure-volume ratio, ESP/ESV) from the specifically linear end-systolic pressure-volume relation in canine hearts [5-9]. In contrast to the linear end-systolic pressure-volume relation in canine hearts, the endsystolic pressure-volume relation in the rat LV is, more generally, curvilinear. We were therefore unable to use $E_{\max }$ for assessing LV contractility in rat hearts. Instead we have already proposed $\mathrm{ESP}_{\mathrm{mLVV}}$ for assessing LV contractility [13-15]. However, this index was 
Table 3. Control $\mathrm{VO}_{2}$-PVA relation at pacing rate of $300 \mathrm{bpm}$ and oxygen cost of left ventricular contractility at pacing rates of 240 and $300 \mathrm{bpm}$.

PVA-independent $\mathrm{VO}_{2}-\mathrm{e} E_{\max }$ relation

\begin{tabular}{|c|c|c|c|c|c|}
\hline \multirow[t]{3}{*}{ Exp. No. } & \multicolumn{2}{|c|}{ Control $\mathrm{VO}_{2}-\mathrm{PVA}$ relation at $\mathrm{HR} 300$} & \multirow{2}{*}{\multicolumn{3}{|c|}{$\begin{array}{l}\text { Slope: } \mathrm{O}_{2} \text { cost of } \mathrm{LV} \text { contractility } \\
\left(\times 10^{-4} \mu \mathrm{l} \mathrm{O}_{2} \cdot \mathrm{ml} \cdot \mathrm{mmHg}^{-1} \cdot \text { beat }^{-1} \cdot \mathrm{g}^{-2}\right) \mathrm{mLVV}\end{array}$}} \\
\hline & \multirow{2}{*}{$\begin{array}{c}\text { Slope } \\
\left(\times 10^{-2} \mu \mathrm{l} \mathrm{O}_{2} \cdot \mathrm{mmHg}^{-1} \cdot \mathrm{ml}^{-1}\right)\end{array}$} & \multirow{2}{*}{$\begin{array}{c}\mathrm{VO}_{2} \text {-intercept } \\
\left(\mu \mid \mathrm{O}_{2} \cdot \text { beat }^{-1} \cdot \mathrm{g}^{-1}\right)\end{array}$} & & & \\
\hline & & & $\mathrm{HR} 240$ & HR 300 & \\
\hline 1 & 1.21 & 0.34 & 0.87 & 0.96 & 0.15 \\
\hline 2 & 1.70 & 0.36 & 1.86 & 2.03 & 0.15 \\
\hline 3 & 0.97 & 0.34 & 1.51 & 1.72 & 0.15 \\
\hline 4 & 0.80 & 0.33 & 1.66 & 1.87 & 0.16 \\
\hline 5 & 0.93 & 0.26 & 1.05 & 1.00 & 0.15 \\
\hline 6 & 0.64 & 0.26 & 1.68 & 1.68 & 0.16 \\
\hline Mean & 1.04 & 0.32 & 1.44 & 1.54 & 0.15 \\
\hline SD & 0.34 & 0.04 & 0.36 & 0.41 & 0.004 \\
\hline
\end{tabular}

Exp. No., experiment number; $\mathrm{HR}$, heart rate; $\mathrm{VO}_{2}$, myocardial oxygen consumption per beat; PVA, pressure-volume area; e $E_{\max }$, equivalent maximal elastance; LV, left ventricle; $\mathrm{mLVV}$, midrange left ventricular volume; SD, standard deviation of the mean values.

insufficient to compare LV contractility among LVs with different volumes. To do this, such an index should have been normalized by LVVs.

On the other hand, $\mathrm{PVA}_{\mathrm{mLVV}}$ has been proposed and used to be a good index for the mechanoenergetic evaluation of rat LV contractility $[1,2,13-15]$. Our recently proposed index for assessing LV contractility,

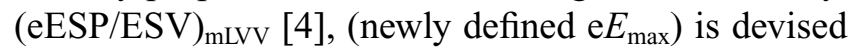
from the curved end-systolic pressure-volume relation and $\mathrm{PVA}_{\mathrm{mLVV}}$. This index depends on LVV in contrast to $E_{\max }$ which is independent of LVV. Therefore we always adopted an mLVV experimentally obtained, where ESP was about $67 \%$ of the maximum ESP as well as in our previous report [4]. This yields a reasonably constant oxygen cost of LV contractility in spite of small deviations in $\mathrm{mLVV}$ values in individual hearts. However, the dependency of the oxygen cost of LV contractility on heart rates has not been investigated yet.

In the present study, we compared oxygen costs of LV contractility at 240 and $300 \mathrm{bpm}$, since the range of heart rates could be varied by pacing, but not widely because of higher sinus rhythm and incomplete relaxation. The pacing rate of $240 \mathrm{bpm}$ should be adopted for the heart from hypothyroid rat [12]. No dependency of the cost on heart rates is expected to compare the oxygen cost of LV contractility under different heart rate conditions.

End-systolic pressure-volume and $\mathrm{VO}_{2}-$ PVA relations at $240-$ and $300-b p m$ pacing. All variables of LV mechanics showed no differences between 240- and 300-bpm pacing, suggesting that
LV end-systolic pressure-volume relation did not differ within 240-300 bpm. In the excised canine hearts, it has been reported that the slope of linear end-systolic pressure-volume relation did not differ within a wide range of heart rates at $105-230 \mathrm{bpm} \mathrm{[10]} \mathrm{and}$ $100-160 \mathrm{bpm}$ [11]. In contrast, in the heart of conscious dogs the linear LV end-systolic pressure-volume relation has shown the progressive increase in its slope and rightward shift at increasing heart rates from 67 to $200 \mathrm{bpm} \mathrm{[17].} \mathrm{However,} \mathrm{we} \mathrm{have} \mathrm{already}$ confirmed that the LV end-systolic pressure-volume relation in in situ rat hearts did not change significantly within $250-320 \mathrm{bpm}$ [14]. The present results coincide with this result [14].

The mean slopes and $\mathrm{VO}_{2}$ intercepts (PVA-independent $\left.V \mathrm{O}_{2}\right)$ of the $V \mathrm{O}_{2}$-PVA relations did not differ within $240-300 \mathrm{bpm}$. These values are similar to those of our previous reports in rat hearts [1,2], though slightly smaller, and those in canine hearts [5-7]. The present results are consistent with a previous study showing that in the excised canine heart, the $\mathrm{VO}_{2}-\mathrm{PVA}$ relation did not significantly differ within 105-230 bpm [10]. In contrast, there is another report showing that $V \mathrm{O}_{2}$ intercept (PVA-independent $V \mathrm{O}_{2}$ ) of the $V_{\mathrm{O}_{2}}$ PVA relation decreased when the heart rate was increased from 60 to $181 \mathrm{bpm}$ with no change in its slope in the excised canine heart [18]. The possible explanation for the decreased $V_{\mathrm{O}_{2}}$ intercept with the increased heart rate was as follows. Basal metabolism includes a certain "basal level" of PVA-independent $V \mathrm{O}_{2}$ related to processes such as ion pumps, whose metabolic cost does vary with heart rate. On the other 
hand, we considered that the PVA-independent $\mathrm{VO}_{2}$ corresponds to the $\mathrm{VO}_{2}$ for total $\mathrm{Ca}^{2+}$ handling in the E-C coupling, basal metabolism, and possibly the $\mathrm{VO}_{2}$ for residual cross-bridge cycling in rat, rabbit, and canine hearts $[1,2,19-23]$. There is a report showing no differences in the resting heat production between unstimulated and stimulated rat LV papillary muscles [24]. We observed no difference in the $\mathrm{VO}_{2}$ for basal metabolism obtained by $\mathrm{KCl}$-arrest hearts under $4 \mathrm{~Hz}$ to $5 \mathrm{~Hz}$-stimulation $(n=7)$. Therefore we conclude that neither the oxygen cost of PVA nor $\mathrm{VO}_{2}$ for $\mathrm{Ca}^{2+}$ handling in the $\mathrm{E}-\mathrm{C}$ coupling and basal metabolism changed at all within 240-300 bpm.

\section{Oxygen cost of LV contractility during $\mathrm{Ca}^{2+}$} infusion at 240 and $300 \mathrm{bpm}$. The oxygen cost of $\mathrm{LV}$ contractility indicates the $V \mathrm{O}_{2}$ needed for total $\mathrm{Ca}^{2+}$ handling in the E-C coupling per unit change in $\mathrm{LV}$ contractility (changes in total $\mathrm{Ca}^{2+}$ handling $\mathrm{VO}_{2}$ in the E-C coupling in proportion to $\mathrm{Ca}^{2+}$ concentration)/(changes in LV contractility in proportion to $\mathrm{Ca}^{2+}$ concentration). We consider that this cost would be changed by a denominator (the myofilament $\mathrm{Ca}^{2+}$ responsiveness) and/or a numerator (the total $\mathrm{Ca}^{2+}$ handling/ATP ratio in the sarcoplasmic reticulum and sarcolemma) $[8,9,25]$. The mean values of oxygen costs of LV contractility in rat hearts at 240 and $300 \mathrm{bpm}$ did not differ and corresponded to our previous one [4] and to oxygen costs of $E_{\max }$ in canine hearts [5-7]. The present results suggest that neither the total $\mathrm{Ca}^{2+}$ handling/ATP ratio nor the myofilament $\mathrm{Ca}^{2+}$ responsiveness changes within 240-300 bpm and that we are able to compare oxygen costs of LV contractility in the heart paced at $240-300 \mathrm{bpm}$ with no correction by heart rate. In in situ hearts, LV contractility and heart rate are changed physiologically by the control of the autonomic nervous system. Under these conditions, heart rate independency of the oxygen cost of LV contractility seems to be critical and indispensable for characterizing LV proper mechanoenergetics. On the basis of the above-mentioned heart rate independency of the oxygen cost of LV contractility, we conclude that even under the different pacing rates within $240-300 \mathrm{bpm}$, this index is valid for assessing cardiac mechanoenergetics, especially the economy of total $\mathrm{Ca}^{2+}$ handling in E-C coupling.

This study was partly supported by a Grant-in-Aid for Scientific Research (11470277) from the Ministry of Education, Science, Sports and Culture, Japan.

\section{REFERENCES}

1. Hata $Y$, Sakamoto $T$, Hosogi $S$, Ohe $T$, Suga $H$, and Takaki M: Linear $\mathrm{O}_{2}$ use-pressure-volume area relation from curved end-systolic pressure-volume relation of the blood-perfused rat left ventricle. Jpn J Physiol 48: 197-204, 1998

2. Hata $Y$, Sakamoto T, Hosogi S, Ohe T, Suga $H$, and Takaki M: Effects of thapsigargin and $\mathrm{KCl}$ on the $\mathrm{O}_{2}$ use of the excised blood-perfused rat heart. J Mol Cell Cardiol 30: 2137-2144, 1998

3. Takaki M, Tachibana H, Hata Y, Sakamoto T, and Suga $\mathrm{H}$ : Mechanoenergetics of rat left ventricles in in situ and excised blood-perfused hearts and in unloaded rat left ventricular slices. Heart Vessels 12 (Suppl): 100-102, 1997

4. Tsuji T, Onga Y, Yoshikawa Y, Sakata S, Kohzuki H, Misawa H, Abe T, Tabayashi N, Kobayashi S, Kitamura S, Taniguchi S, Suga H, and Takaki M: New index for oxygen cost of contractility from curved end-systolic pressure-volume relations in cross-circulated rat hearts. Jpn J Physiol 49: 513-520, 1999

5. Araki J, Takaki M, Namba T, Mori M, and Suga $\mathrm{H}: \mathrm{Ca}^{2+}$ free, high- $\mathrm{Ca}^{2+}$ coronary perfusion suppresses contractility and excitation-contraction coupling energy. Am J Physiol 268 (Heart Circ Physiol 37): H1061-H1070, 1995

6. Nakayama Y, Takaki M, Kohno K, Araki J, and Suga H: Mechanoenergetics of the negative inotropism of isoflurane in the canine left ventricle. $\mathrm{No} \mathrm{O}_{2}$ wasting effect. Anesthesiology 87: 82-93, 1997

7. Namba T, Takaki M, Araki J, Ishioka K, and Suga H: Energetics of the negative and positive inotropism of pentobarbitone sodium in the canine left ventricle. Cardiovasc Res 28: 557-564, 1994

8. Suga H: Ventricular energetics. Physiol Rev 70: 247-277, 1990

9. Takaki M, Matsubara $H$, Araki J, Zhao LY, Ito H, Yasuhara S, Fujii W, and Suga $\mathrm{H}$ : Mechanoenergetics of acute failing hearts characterized by oxygen costs of mechanical energy and contractility. In: New Horizons for Failing Heart Syndrome, ed. Sasayama S, SpringerVerlag, Tokyo, pp 133-164, 1996

10. Suga H, Hisano R, Hirata S, Hayashi T, Tamada O, and Ninomiya I: Heart rate-independent energetics and systolic pressure-volume area in dog heart. Am J Physiol 244 (Heart Circ Physiol 13): H2O6-H214, 1983

11. Suga $H$, Sagawa $K$, and Shoukas AA: Load independence of the instantaneous pressure-volume ratio of the canine left ventricle and effects of epinephrine and heart rate on the ratio. Circ Res 32: 314-322, 1973

12. Ohga $Y$, Sakata S, Kohzuki H, Misawa H, and Takaki M: Left ventricular mechanoenergetics in cross-circulated excised hypothyroid rat hearts. Jpn J Physiol 49 (Suppl): S73, 1999

13. Fujii W, Takaki M, Yoshida $A$, Ishidate $H$, Ito $H$, and Suga $\mathrm{H}$ : Effects of intracoronary caffeine on left ventricular mechanoenergetics in $\mathrm{Ca}^{2+}$ overload failing rat hearts. Jpn J Physiol 48: 373-381, 1998

14. Lee $S$, Ohga $Y$, Tachibana $H$, Syuu $Y$, Ito $H$, Harada $M$, Suga $H$, and Takaki M: Effects of myosin isozyme shift on curvilinearity of the left ventricular end-systolic pressure-volume relation of in situ rat hearts. Jpn J Physiol 48: 445-455, 1998

15. Tachibana $H$, Takaki $M$, Lee $S$, Ito $H$, Yamaguchi $H$, and Suga $\mathrm{H}$ : New mechanoenergetic evaluation of left ventricular contractility in in situ rat hearts. Am J Physiol 272 (Heart Circ Physiol 41): H2671-H2678, 1997 
16. Suga $H$, Yamada $O$, Goto $Y$, and Igarashi $Y$ : Peak isovolumic pressure-volume relation of puppy left ventricle. Am J Physiol 25 (Heart Circ Physiol 19): $\mathrm{H} 167-\mathrm{H} 172,1986$

17. Freeman GL, Little WC, and O'Rourke RA: Influence of heart rate on left ventricular performance in conscious dogs. Circ Res 61: 455-464, 1987

18. Harasawa Y, de Tombe PP, Sheriff DD, and Hunter WC: Basal metabolism adds a significant offset to unloaded myocardial oxygen consumption per minute. Circ Res 71: 414-422, 1992

19. Higashiyama A, Watkins MW, Chen Z, and Lewinter MM: Preload does not influence nonmechanical $\mathrm{O}_{2}$ consumption in isolated rabbit heart. Am J Physiol 266 (Heart Circ Physiol 35): H1047-H1054, 1994

20. Nozawa T, Yasumura Y, Futaki S, Tanaka N, and Suga $\mathrm{H}$ : No significant increase in $\mathrm{O}_{2}$ consumption of $\mathrm{KCl}$-arrested dog heart with filling and dobutamine. Am J Physiol 255 (Heart Circ Physiol 24): H807-H812, 1988

21. Takaki M, Kohzuki H, Kawatani Y, Yoshida A, Ishidate $\mathrm{H}$, and Suga $\mathrm{H}$ : Sarcoplasmic reticulum $\mathrm{Ca}^{2+}$ pump blockade decreases $\mathrm{O}_{2}$ use of unloaded contracting rat heart slices: thapsigargin and cyclopiazonic acid. J Mol Cell Cardiol 30: 649-659, 1998

22. Yasuhara S, Takaki M, Kikuta A, Ito $H$, and Suga $H$ : Myocardial $\mathrm{VO}_{2}$ of mechanically unloaded contraction of rat ventricular slices measured by a new approach. Am J Physiol 270 (Heart Circ Physiol 39): H1063-H1070, 1996

23. Kohzuki $H$, Misawa $H$, Sakata S, Ohga $Y$, Suga $H$, and Takaki M: Energy expenditure by barium contracture in rat ventricular slices derives from crossbridge cycling. Am J Physiol 277 (Heart Circ Physiol 46): H74-H79, 1999

24. Loiselle DS: The rate of resting heat production of rat papillary muscle. Pflügers Arch 405: 155-162, 1985

25. Shimizu J, Araki J, Mizuno J, Lee S, Syuu Y, Hosogi S, Mohri S, Mikane T, Takaki M, Taylor TW, and Suga H: A new integrative method to quantify total $\mathrm{Ca}^{2+}$ handling and futile $\mathrm{Ca}^{2+}$ cycling in failing hearts. Am J Physiol 275 (Heart Circ Physiol 44): H 2325-H2333, 1998 